\section{Urogenital symptoms in postmenopausal women: a hospital-based prevalence study}

Nisarath Soontrapa, Sukree Soontrapa, Srinaree Kaewrudee, Woraluk

Somboonporn, Chuanchom Sakondhavat

Department of Obstetrics and

Gynecology, Faculty of Medicine, Khon

Kaen University, Khon Kaen, Thailand

\section{Abstract}

Objectives. To determine the prevalence of urogenital symptoms (vaginal dryness, dyspareunia, urinary incontinence) and assess patient's consultation rate and desire for treatment.

Design and Methods. This study was prospective descriptive study, performed with the participation of 125 women who presented in menopausal clinic, Srinagarind Hospital. Women completed the questionnaire including questions about their demographic properties and were interviewed by pre-validated questionnaire and in-depth interview to determine the prevalence of urogenital symptoms, consultation rate and patient's desire for treatment. Results. The mean age of the participants was 57.1 years. Vaginal dryness was found to be the most common postmenopausal urogenital symptoms (71.2\%), followed by urinary incontinence (62.4\%) and dyspareunia $(52.0 \%)$. The consultation rates were $62.2 \%$ in vaginal dryness, $46.2 \%$ in dyspareunia and $38.5 \%$ in urinary incontinence. Patient's desire for treatment was $66.7 \%$ in vaginal dryness, $62.1 \%$ in dyspareunia and $53.8 \%$ in urinary incontinence.

Conclusions. Urogenital symptoms are highly prevalent. Physicians need to improve patient-physician communication and increase their attention to these symptoms and their patient's attitudes to improve patient's quality of life.

\section{Introduction}

The interest in menopausal problems has increased in recent years, due to expansion of human life-span. Women are spending more than one-third of their lives in menopausal period. ${ }^{1,2}$ Urogenital (UG) symptoms are one of the most common symptoms of menopause. These symptoms include vaginal dryness, itching, dyspareunia and urinary incontinence (UI) ${ }^{2-5}$ Women's health initiative study (WHI) showed that the prevalence of vaginal dryness was $27.0 \%$, irritation $18.6 \%$ and vaginal discharge $11.1 \% .^{3}$ Although UG symptoms are common among menopausal symptoms, there are relatively few studies on this subject in the literature compared with other symptoms ${ }^{4}$ even though UG symptoms can be relieved rapidly after local estrogen administration. ${ }^{5}$ UG symptoms do not pose direct threat to life but have negative impact on quality of life (QOL) such as personal distress and discomfort. ${ }^{6}$ Previous studies showed that many affected individuals fail to report this condition to their physicians and often endure the inconvenience and unpleasantness of symptoms for many years. ${ }^{7}$ This may be because they are embarrassed or possibly because of the mistaken opinion that effective treatment is not available or UG symptoms are only the normal aging process. ${ }^{7}$ The primary objective of this study was to assess the prevalence of UG symptoms (vaginal dryness, dyspareunia, urinary incontinence) and the secondary objective was to assess patient's consultation rate and their desire for treatment. To guide future effort to reduce their impact on QOL, we also tried to find out women's believes about the etiology of symptoms and strategies for coping with symptoms in order to understand how these believes and attitudes might influence their discussion with health care providers.

\section{Materials and Methods}

This prospective descriptive study was performed in menopausal clinic, Department of Obstetrics and Gynecology, Srinagarind hospital from July 2010 to October 2010. A total of 125 women who matched with the definition of natural or surgical menopause were recruited in the study and completed questionnaires via a face-to-face interview. (Natural menopause was defined as the women who did not have menstruation for at least 1 year. Surgical menopause was defined as menopause after bilateral oophorectomy with or without hysterectomy). The questionnaire contained questions about their demographic data including age, age of menopause, weight, height, number of pregnancies and births, route of delivery, marital status, educational level and income via open-ended questions. Urogenital symptoms assessment included vaginal dryness, dyspareunia, and urinary incontinence. Each symptom was assessed by asking whether it had occurred within the past 4 weeks and assessed the prevalence, severity (mild symptom defined as symptom less than twice a week, moderate symptom as symptom between 3-5 days/week and severe symptom as more than 6 days/week.), impact on QOL (based on ICIQ questionnaires ${ }^{8}$ ), patient's atti-
Correspondence: Nisarath Soontrapa, Department of Obstetrics and Gynecology, Faculty of Medicine, Khon Kaen University, Khon Kaen 40002, Thailand.

Tel. +66.4.33633030 - Fax: +66.4.3348395.

E-mail:pui_pika@hotmail.com

Key words: Urogenital symptoms, vaginal dryness, dyspareunia, urinary incontinence, postmenopausal women.

Contribution: NS, research design and performing, data analysis and manuscript writing; SS, research design and data analysis; SK, WS, CS, final manuscript examination. All authors read and approved the final manuscript.

Conflict of interest: the authors report no conflicts of interest.

Received for publication: 9 August 2011. Accepted for publication: 11 0ctober 2011.

This work is licensed under a Creative Commons Attribution NonCommercial 3.0 License (CC BYNC 3.0).

(C) Copyright N. Soontrapa et al., 2011

Licensee PAGEPress, Italy

Urogynaecologia 2011; 25:e13

doi:10.4081/uij.2011.e13

tudes (in-depth interview), patient's knowledge, patient's consultation rate, previous treatment (hormone therapy) and patient desire for treatment of each UG symptoms. Data were analyzed by computerized program (SPSS 10.0), the $\chi^{2}$-test was the statistical test of choice. A value of $\mathrm{P}<0.05$ was set as the significance criterion. The data were presented as mean \pm SD or percentage. All study procedures were approved by the Human ethical committee of faculty of medicine Khon Kaen University.

\section{Results}

The mean age of the participants was 57.1 years. The baseline clinical characteristics of 125 participated women were shown in Table 1 and demographic data in correlation with each urogenital symptom were shown in Table 2 . The prevalence of each urogenital symptom and its severity were shown in Table 3 . The most common reported urogenital symptom was vaginal dryness (71.2\%), followed by urinary incontinence $(62.4 \%)$, and dyspareunia (52.0\%). The severity of vaginal dryness was shown in Table 3 . From the patient with vaginal dryness, $41.0 \%$ weren't concerned with this symptom, $40.8 \%$ reported that vaginal dryness had no effect on daily living and $28.8 \%$ had 
moderate to severe effect to their daily living (59.2\%). Of those individuals with vaginal dryness, $62.2 \%$ had consulted a medical practitioner about their symptoms (Figure 1). The most common reason given by the participants for not seeking help was the belief that vaginal dryness was not the life threatening symptoms (66.7\%) follows by the embarrassment (14.3\%). Patients who had consulted a doctor were currently taking medication (60.7\%), $56 \%$ of patients in this group had completely recovery, $12 \%$ had some relief from their symptom and $32 \%$ had no change in their symptom. Among $39.3 \%$ of patients currently not on medication, $66.7 \%$ wanted treatment and $33.3 \%$ did not want any treatment. For dyspareunia, the prevalence was $52 \%$ (mild symptom $23.2 \%$, moderate symptom $20 \%$ and severe symptom $8.8 \%$ in Table 2). With $53.7 \%$ of the participants had some adverse effects to their QOL and $53.8 \%$ of the women with dyspareunia did not speak to doctor due to mild symptom (48.8\%) and embarrassment (31.7\%). Regarding medical attention 55.2\% had received treatment with $21.6 \%$ reporting complete recovery, partial recovery in $75.7 \%$ and no recovery $2.7 \%$. Among $44.8 \%$ of participants currently not on medication, $62.1 \%$ wanted treatment and $37.9 \%$ did not want any treatment. When urinary symptoms were analyzed, the prevalence of urinary incontinence was $62.4 \%$ among these $42.8 \%$ having urge incontinence, $53.3 \%$ having stress incontinence and $3.8 \%$ having mixed urinary incontinence. According to points obtained from QOL instrument, UI had only mild impacts upon the QOL of women (no impact $65.4 \%$, mild $24.4 \%$ and moderate to severe $10.2 \%$ ). QOL was determined to be negatively affected most in sub-

Table 1. Baseline clinical characteristics of participants.

\begin{tabular}{|c|c|c|}
\hline Characteristic & $N(=125)$ & $\%$ \\
\hline $\begin{array}{l}\text { Age group (year) } \\
\quad \leq 49 \\
50-59 \\
\geq 60\end{array}$ & $\begin{array}{l}15 \\
60 \\
50\end{array}$ & $\begin{array}{l}12.0 \\
48.0 \\
40.0\end{array}$ \\
\hline $\begin{array}{l}\text { Type of menopause } \\
\text { Natural menopause } \\
\text { Surgical menopause }\end{array}$ & $\begin{array}{l}85 \\
40\end{array}$ & $\begin{array}{l}68.0 \\
32.0\end{array}$ \\
\hline $\begin{array}{l}\text { Marital status } \\
\text { Married } \\
\text { Divorced/widow }\end{array}$ & $\begin{array}{l}99 \\
26\end{array}$ & $\begin{array}{l}79.2 \\
20.8\end{array}$ \\
\hline $\begin{array}{l}\text { Mode of delivery } \\
\text { Vaginal route } \\
\text { C/S route } \\
\text { Both }\end{array}$ & $\begin{array}{l}94 \\
12 \\
5\end{array}$ & $\begin{array}{l}84.7 \\
10.8 \\
4.5\end{array}$ \\
\hline $\begin{array}{l}\text { Number of births } \\
\quad 0-2 \\
\geq 3\end{array}$ & $\begin{array}{l}74 \\
51\end{array}$ & $\begin{array}{l}59.2 \\
40.8\end{array}$ \\
\hline $\begin{array}{l}\text { Educational status } \\
\text { Primary graduate school } \\
\text { High school graduate } \\
\text { University graduate }\end{array}$ & $\begin{array}{l}39 \\
26 \\
60\end{array}$ & $\begin{array}{l}31.2 \\
20.8 \\
48.0\end{array}$ \\
\hline
\end{tabular}

domains of daily life activity, social embarrassment, avoidance and limiting behavior and psychosocial impacts. Of these groups, only $38.5 \%$ of patients with UI informed their symptoms to doctors, $31.3 \%$ received treatment with 61.5\% reporting partially improved symptom and $19.4 \%$ were symptom free after treatment.

\section{Discussion}

This study found that the urogenital symptoms had high prevalence (vaginal dryness $71.2 \%$, dyspareunia $52.0 \%$ and UI $62.4 \%$ ). Vaginal dryness is one of the most common problems in postmenopausal women. ${ }^{5}$
Approximately $20-40 \%$ of postmenopausal women worldwide experience this problem. ${ }^{7,8}$ Our overall $71.2 \%$ prevalence of vaginal dryness was higher than that reported previously. $3,4,7,8$ The higher prevalence reported in this study may reflect the method of data collection. Although our study was a descriptive study, data was collected not only from a pre-validated questionnaire but also from in-depth interviews so the participants were able to ask question if they didn't understand any point in the question. Another reason might be that the participants were the women in menopausal clinic so the prevalence might be higher than general population. For dyspareunia the overall prevalence rate of this study was $52 \%$ which was similar to a previous study by Molrudee $e t$

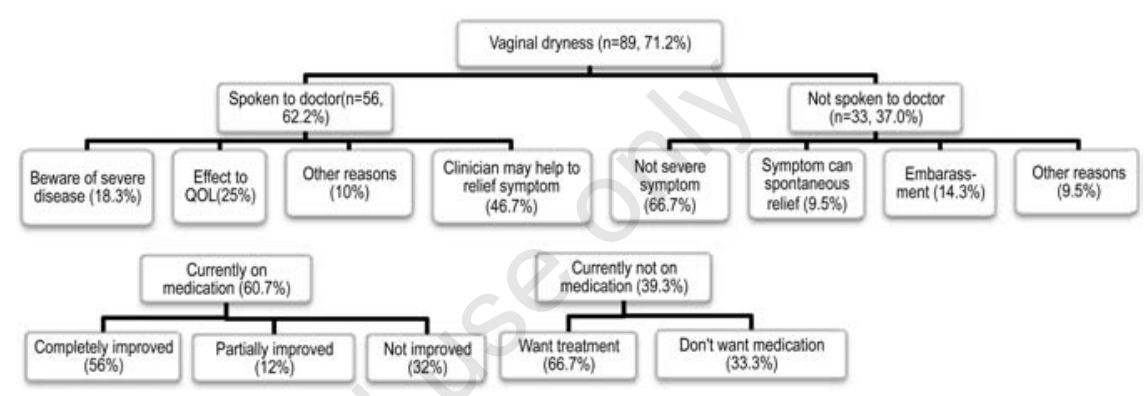

Figure 1. Prevalence of medical consultation and current medication in 89 women with vaginal dryness.

Table 2. Demographic data in correlation with each urogenital symptom (vaginal dryness, dyspareunia and urinary incontinence).

\begin{tabular}{|c|c|c|c|c|c|c|}
\hline \multirow[t]{2}{*}{$\begin{array}{l}\text { Demographic } \\
\text { data }\end{array}$} & \multicolumn{2}{|c|}{$\begin{array}{l}\text { Vaginal } \\
\text { dryness }\end{array}$} & \multicolumn{2}{|c|}{ Dyspareunia } & \multicolumn{2}{|c|}{$\begin{array}{c}\text { Urinary } \\
\text { incontinence }\end{array}$} \\
\hline & Symptom & No symptom & Symptom & No symptom & Symptom & No symptom \\
\hline $\begin{array}{l}\text { Age (mean } \\
\text { age (yr) } \pm \text { SD ) }\end{array}$ & $56.75 \pm 7.08$ & $58.25 \pm 7.23$ & $55.83 \pm 6.81$ & $58.24 \pm 6.89$ & $59.47 \pm 6.59$ & $55.33 \pm 6.67$ \\
\hline $\begin{array}{l}\text { Age at } \\
\text { menopause }\end{array}$ & $47.39 \pm 4.96$ & $47.38 \pm 4.97$ & $47.42 \pm 4.61$ & $47.48 \pm 5.34$ & $48.43 \pm 4.47$ & $46.69 \pm 4.75$ \\
\hline $\begin{array}{l}\text { Type of menopause } \\
\text { Natural (\%) } \\
\text { Surgical (\%) }\end{array}$ & $\begin{array}{l}70.59 \\
72.50\end{array}$ & $\begin{array}{l}29.41 \\
27.50\end{array}$ & $\begin{array}{l}49.41 \\
52.50\end{array}$ & $\begin{array}{l}50.59 \\
47.50\end{array}$ & $\begin{array}{l}61.18 \\
62.50\end{array}$ & $\begin{array}{l}38.82 \\
37.50\end{array}$ \\
\hline BMI $\left(\mathrm{Kg} / \mathrm{m}^{2}\right)$ & $23.43 \pm 3.36$ & $24.78 \pm 3.79$ & $22.95 \pm 3.32$ & $24.83 \pm 3.79$ & $24.38 \pm 3.24$ & $23.66 \pm 4.24$ \\
\hline $\begin{array}{l}\text { Educational status } \\
\text { (\% symptom) } \\
\text { Primary graduate school } \\
\text { High school graduate } \\
\text { University graduate }\end{array}$ & $\begin{array}{l}61.54 \\
76.47 \\
52.78\end{array}$ & $\begin{array}{l}38.46 \\
23.53 \\
47.22\end{array}$ & $\begin{array}{l}48.72 \\
41.18 \\
53.62\end{array}$ & $\begin{array}{l}51.28 \\
58.82 \\
46.38\end{array}$ & $\begin{array}{l}66.67 \\
47.06 \\
43.49 \\
\end{array}$ & $\begin{array}{l}33.33 \\
52.94 \\
56.51\end{array}$ \\
\hline
\end{tabular}

Table 3. Prevalence of vaginal dryness, dyspareunia, urinary incontinence and severity correlated with each symptoms.

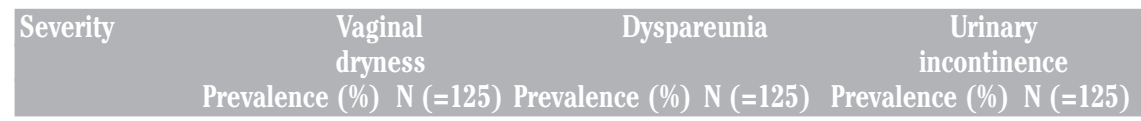

\begin{tabular}{|c|c|c|c|c|c|c|}
\hline No symptom & 28.8 & 36 & 48.0 & 60 & 37.6 & 47 \\
\hline $\begin{array}{l}\text { With symptoms } \\
(95 \% \text { CI })\end{array}$ & $\begin{array}{c}71.2 \\
(63.3-79.1)\end{array}$ & 89 & $\begin{array}{c}52 \\
(43.2-60.8) \\
\end{array}$ & 65 & $\begin{array}{c}62.4 \\
(53.9-70.9)\end{array}$ & 78 \\
\hline Mild symptom & 28.0 & 35 & 23.2 & 29 & 35.2 & 44 \\
\hline Mod. Symptom & 29.6 & 37 & 20.0 & 25 & 13.6 & 17 \\
\hline Severe symptom & 13.6 & 17 & 8.8 & 11 & 13.6 & 17 \\
\hline
\end{tabular}


$a l .{ }^{9}$ but different from the other literatures that reported dyspareunia increase until age 60 and then stable at a rate of only $10 \% .^{10,11}$ The difference might be due to the same reason as with vaginal dryness. UI rate in postmenopausal women was reported vary between $10 \%$ and $50 \%$ and stress UI was $48-60 \% .^{3,5,7,12}$ When compared with this study, the prevalence of UI and stress UI were similar to previous study. $1,5,7,12$ When evaluating the patient's attitude and Q0L, at least $34.6 \%$ of participants with one or more UG symptom reported that their condi- tion adversely affected their daily life. These findings clearly indicate that sufferers consider these symptoms to be bothersome and affect their well-being. The consultation rates in this study were higher than expected (vaginal dryness $62.2 \%$, dyspareunia $46.2 \%$ and UI $38.5 \%$ ). The main reason for consultation was on the belief that physician could help them to relief the symptoms (as high as $46.7 \%$ in vaginal dryness), the next reason was these symptoms effected to their QOL. In the other group, the main reasons for not seeking for medication

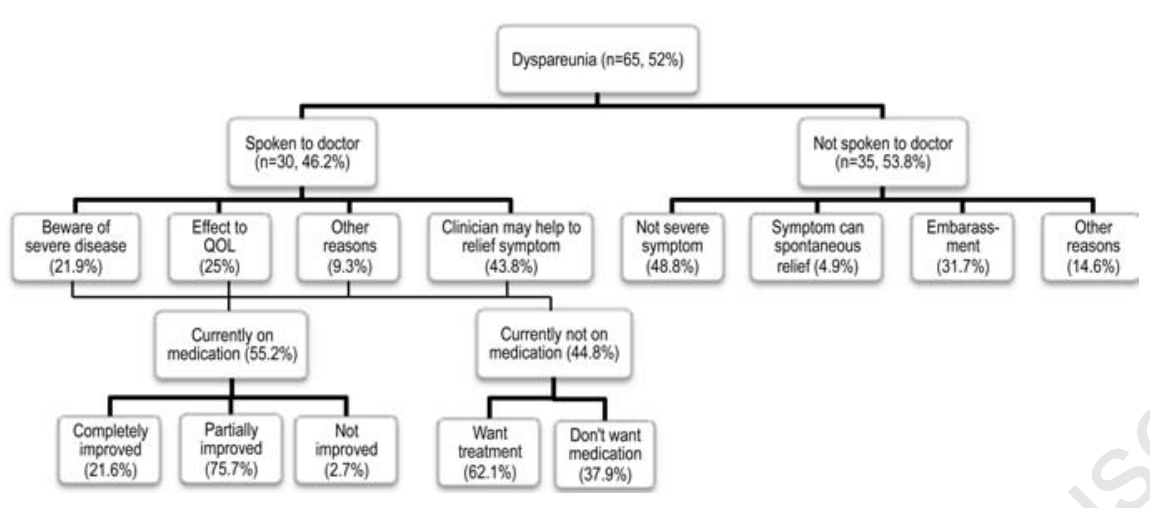

Figure 2. Prevalence of medical consultation and current medication in 65 women with dyspareunia.

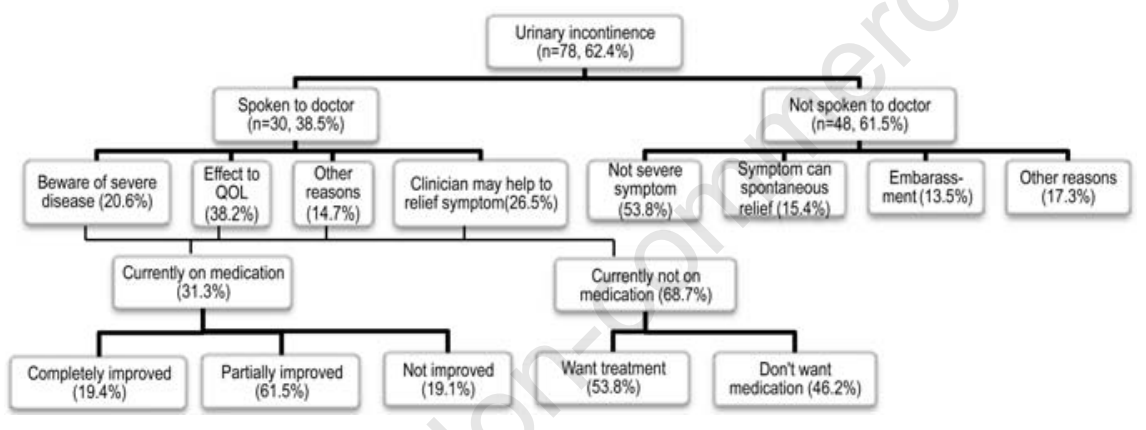

Figure 3. Prevalence of medical consultation and current medication in 78 women with urinary incontinence.

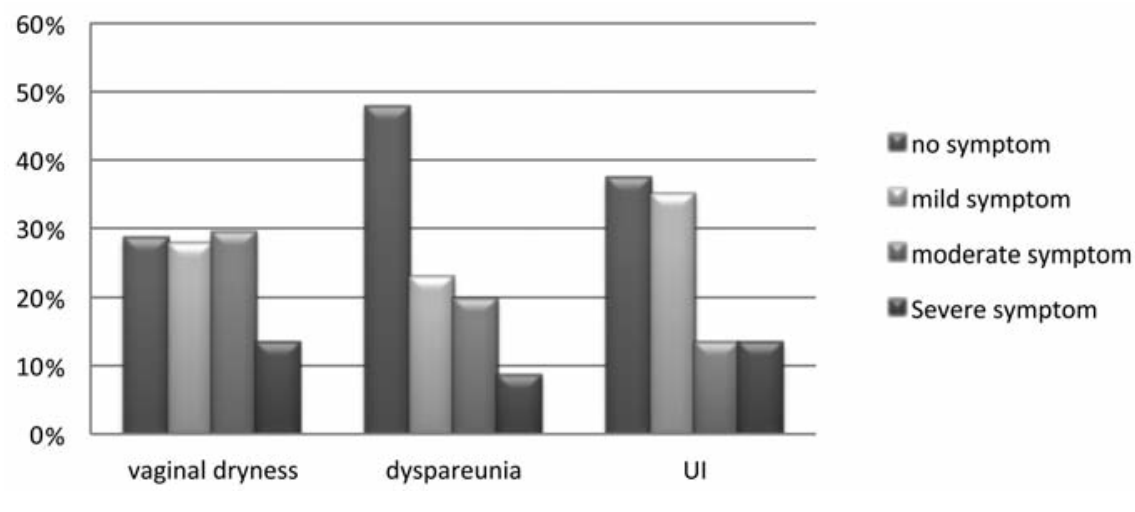

Figure 4. Prevalence of urogenital symptoms. are not severe symptoms and symptoms can spontaneous relief. The others might be due to the embarrassment and misconception that their symptoms were only normal aging process. For individuals who had sought advice such as in vaginal symptom, $60.7 \%$ was currently receiving medication and as high as $56.0 \%$ had completely recovery from their symptoms indicating that these problems are treatable and patient will have better QOL if only physicians pay more attention to these symptoms. When evaluate in participants who sought for advice but currently not on medication, at least $53.8 \%$ wanted further treatment this data may reflect that physicians or even health care providers abandon or underestimate for these symptoms. Although our study was one in a few groups of study that concerned patient's consultation rate and prevalence of patient's seeking for medication in UG symptoms, but the limitations of this study were the populations in this study were in menopausal clinic so it can't reflect to all menopausal women and the method used to classify the type of UI by using a series of detailed questions and assessed the patients by clinical symptoms without any clinical examination and urodynamic investigation.

\section{Conclusions}

This study confirmed that urogenital symptoms are highly prevalent, our results suggest that physicians need to increase their attention to patient's urogenital symptoms and menopausal attitudes and general health believes. Improved patient-physician relationship may assist women in making decisions to discuss these symptoms with their physician to enhance their quality of life.

\section{References}

1. Sakondhavat C, Choosuwan C, Kaewrudee S, Soontrapa S, Louanka K. Prevalence and risk factors of urinary incontinence in Khon Kaen menopausal women. J Med Assoc Thai 2007;90:2553-8.

2. Nappi RE, Lachowsky M. Menopause and sexuality: Prevalence of symptoms and impact on quality of life. Maturitas 2009; 63:138-41.

3. Pastore LM, Carter RA, Hulka BS, Wells E. Self-reported urogenital symptoms in postmenopausal women: Women's Health Initiative. Maturitas 2004;49:292-303.

4. Bozkurt N, Ozkan S, Korucuoglu U, et al. Urogenital symptoms of postmenopausal women in Turkey. Menopause 2007;14: 150-6. 
5. Voorhis BJV. Genitourinary symptoms in the menopausal transition. Am J Med 2005; 118:475-535.

6. Huang AJ, Luft J, Grady D, Kuppermann M. The day-to-day impact of urogenital aging: Perspectives from racially/ethnically diverse women. JGIM 2009;14:123-30.

7. Milsom I, Abrams P, Cardozo L, Roberts RG, Thuroff J, Wein AJ. How widespread are the symptoms of an overactive bladder and how are they managed? A populationbased prevalence study. BJU Int 2001;

\section{7:760-6.}

8. Avery K, Donovan J, Peters TJ, Shaw C, Gotoh M, Abrams P. ICIQ: A brief and robust measure for evaluating the symptoms and impact of urinary incontinence. Neurourol Urodyn 2004;23:322-30.

9. Prasit M, Sakondhavat C, Lao-unka K, et al. Menopausal symptoms among women attending of the menopausal clinic at Srinagarind Hospital. Srinagarind Med J 2007;22:267-74.

10. Ghali WA, Freund KM, Boss RD, Ryan CA,
Moskowitz MA. Menopausal hormone therapy: Physician awareness of patient attitudes. Am J Med 1997;103:3-9.

11. Ettinger B, Hait H, Reapr KZ, Shu H. Measuring symptom relief in studies of vaginal and vulvar atrophy: the most bothersome symptom approach. Menopause 2008;15:885-9.

12. Ozerdogan N, Beji NK, Yalcin 0. Urinary incontinence: Its prevalence, risk factors and effects on the quality of life of women living in a region of Turkey. Gynecol Obstet 